\title{
A Case-matched Series of Total Body CT Scanning in Trauma Patients: Reply
}

\author{
J. C. Sierink · J. C. Goslings
}

Published online: 8 July 2014

(C) Société Internationale de Chirurgie 2014

\section{Dear colleagues}

Thank you for your interesting Letter to the Editor regarding our study entitled A Case-Matched Series of Immediate Total-Body CT Scanning versus the Standard Radiological Work-Up in Trauma Patients [1], published in World Journal of Surgery.

We fully agree with the authors that radiation dose is a point of interest. However, another recent study of our group showed that radiation dose during total index admission was comparable between severely injured patients who received a total-body computed tomography (CT) scan and patients who underwent the conventional work-up supplemented by selective CT scanning [2]. This is probably due to the more complete overview of all possible injuries that is obtained with total-body CT scanning at the trauma room.

Furthermore, we acknowledge that not all trauma centers have a CT scanner available in their emergency department or in the trauma resuscitation room itself like we do [3]. Nevertheless, several studies show a time benefit of total-body CT scanning compared with conventional imaging and selective CT scanning [4, 5]. Furthermore, an increasing number of level-one trauma centers do have a CT scanner in the emergency department, and, particularly in those centers, the severely injured patients involved are admitted.

Currently, we are analyzing the results of the REACT-2 trial [6], where patients were randomized between the conventional work-up supplemented by selective CT scanning and immediate total-body CT scanning. The results of this randomized controlled trial are expected at the end of 2014.

\section{References}

1. Sierink JC, Saltzherr TP, Beenen LF et al (2014) A case-matched series of immediate total-body CT scanning versus the standard radiological work-up in trauma patients. World J Surg 38(4):795-802. doi:10.1007/s00268-013-2310-4

2. Sierink JC, Saltzherr TP, Wirtz MR, Streekstra GJ, Beenen LF, Goslings JC (2013) Radiation exposure before and after the introduction of a dedicated total-body CT protocolin multitrauma patients. Emerg Radiol 20(6):507-512

3. Fung Kon Jin PH, Goslings JC, Ponsen KJ, van Kuijk C, Hoogerwerf N, Luitse JS (2008) Assessment of a new trauma workflow concept implementing a sliding CT scanner in the trauma room: the effect on workup times. J Trauma 64(5):1320-1326

4. Healy DA, Hegarty A, Feeley I, Clarke-Moloney M, Grace PA, Walsh SR (2014) Systematic review and meta-analysis of routine total body CT compared with selective CT in trauma patients. Emerg Med J 31(2):101-108

5. van Vugt R, Kool DR, Deunk J, Edwards MJ (2012) Effects on mortality, treatment, and time management as a result of routine use of total body computed tomography in blunt high-energy trauma patients. J Trauma Acute Care Surg 72(3):553-559

6. Sierink JC, Saltzherr TP, Beenen LF, Luitse JS, Hollmann MW, Reitsma JB, Edwards MJ, Hohmann J, Beuker BJ, Patka P, Suliburk JW, Dijkgraaf MG, Goslings JC, REACT-2 study group (2012) A multicenter, randomized controlled trial of immediate total-body CT scanning in trauma patients (REACT-2). BMC Emerg Med 12:4
J. C. Sierink $(\bowtie)$ · J. C. Goslings

Trauma Unit, Department of Surgery, Academic Medical Center, Amsterdam, Netherlands

e-mail: j.c.sierink@amc.nl 